\title{
Kajian Potensi Interaksi Obat pada Pasien Gagal Ginjal Rawat Jalan RS "X" Kota Cirebon
}

\section{Study of Drug Interaction Potency Among Chronic Kidney Disease Patients in The Outpatient Of " $X$ " Hospital Cirebon City}

\author{
Nur Rahmi Hidayati*, Rinto Susilo, Mila Anggraeni \\ Program Studi Farmasi, STF Muhammadiyah Cirebon, Jl Cideng Indah No 3, Cirebon, Indonesia \\ *E-mail: nurrahmihidayati83@mail.com
}

Received: 18 Desember 2020; Accepted: 26 Desember 2020; Published: 31 Desember 2020

\begin{abstract}
Abstrak
Interaksi obat merupakan salah satu bagian dari Drug Related Problem (DRP) yang secara nyata maupun potensial mempengaruhi perkembangan kesehatan pasien. Penelitian ini bertujuan untuk mengetahui karakteristik pasien, gambaran jumlah kejadian potensi interaksi obat, gambaran jenis dan jumlah obat lain yang berinteraksi, dan tingkat keparahan interaksi obat pada pasien gagal ginjal di Rawat Jalan RS " $X$ " Kota Cirebon. Penelitian ini menggunakan 126 resep pasien. Jenis penelitian merupakan penelitian non eksperimental dengan metode analisis deskriptif, dan menggunakan metode pengambilan data dengan teknik sampel random sampling secara prospektif di Rawat Jalan RS "X" Kota Cirebon. Hasil penelitian menunjukkan karakteristik pasien gagal ginjal jenis kelamin terbanyak adalah laki-laki sebanyak 64 orang $(50,79 \%)$, usia paling banyak pada rentang umur $61-70$ tahun sebanyak 38 orang $(30,16 \%)$, adanya interaksi obat 78 lembar resep $(61,9 \%)$, tingkat keparahan interaksi obat paling banyak adalah monitor ketat / signifikan sebanyak 128 kejadian (64,65\%), rata-rata kejadian interaksi obat per lembar resep sebanyak 3 kejadian interaksi, Jenis dan jumlah obat yang paling banyak berinteraksi adalah obat furosemide+folic acid sebanyak 32 potensi kejadian interaksi $(41,02 \%)$.
\end{abstract}

Kata Kunci: Gagal Ginjal, Interaksi Obat, Pasien rawat jalan.

\begin{abstract}
Drug interactions are one of part of Drug Related Problem (DRP) which significantly affect the development patient health. This study aims to determine the characteristics of kidney failure patients (age and genitals), an overview of the number of potential drug interactions, an overview of the types and amounts of other drugs interacting, and the severity of drug interactions in kidney failure patients in the Outpatient of " $X$ " Hospital Cirebon City. This study involves 126 patient prescriptions. This type of research is a non-experimental research with descriptive analysis method, and using data collection methods with prospective random sampling technique in the Outpatient of $R S$ " $X$ " Cirebon. The results of the research from 126 samples obtained showed that the characteristics of Kidney Failure patients were predominantly male as many as 64 people (50.79\%), the most age was in the age range 61-70 years as many as 38 people (30.16\%). drug interactions 78 sheets of prescriptions (61.9\%), the most severity of drug interactions was the strict / significant monitoring of 128 events (64.65\%), the average of drug interactions per prescription sheet was 3 interactions, the type and number of the most interacting drug was furosemide + folic acid with 32 potential interactions (41.02\%).
\end{abstract}

Keywords: Kidney Failure, Drug Interaction, outpatient

\section{PENDAHULUAN}

Gagal ginjal merupakan suatu penyakit fungsi organ ginjal mengalami penurunan hingga akhirnya tidak lagi mampu bekerja sama sekali dalam hal penyaringan pembuangan elektrolit tubuh, menjaga keseimbangan cairan dan zat kimia tubuh seperti sodium dan kalium di dalam darah atau reproduksi urin (NKF, 2016).

Berdasarkan data Riset Kesehatan Dasar (RISKESDAS) pada tahun 2013 prevalensi gagal ginjal di Indonesia sebesar 0,2\% (Kementerian Kesehatan RI, 2013). Menurut Indonesian Renal Registry (IRR) prevalensi 
gagal ginjal di Indonesia pada tahun 2012 sebanyak 28.782 orang. Di provinsi Jawa Barat pada tahun 2011 tercatat sebanyak 3.038 penderita gagal ginjal (Indonesian Renal Registry, 2012).

Pasien dengan gagal ginjal terkadang sering diresepkan banyak obat. Banyaknya penggunaan obat-obatan tersebut, dapat meningkatkan risiko interaksi obat (Bailie et al., 2004). Interaksi obat dianggap penting secara klinik bila berakibat meningkatkan toksisitas dan atau mengurangi efektivitas obat yang berinteraksi terutama bila menyangkut obat dengan batas keamanan yang sempit (indeks terapi yang rendah) (Mariam, 2016).

Berdasarkan penelitian Pasangka,dkk (2017) diketahui potensi interaksi obat yang terjadi sebanyak 292 potensi interaksi obat dengan persentase $65,32 \%$. Berdasarkan penelitian Fatimah (2019) diperoleh hasil potensi interaksi obat ditemukan pada $56 \%$ pasien dengan total 287 kasus. Berdasarkan penelitian Maifitrianti (2016) dari 63 pasien, teridentifikasi sebanyak 443 terdapat interaksi obat. Berdasarkan penelitian Adibe et al (2017) diperoleh hasil dari 169 pasien diperoleh 749 kejadian interaksi obat, dengan 525 kejadian $(70,09 \%)$ tingkat keparahan signifikan. Busari et al (2019), menyebutkan dari 542 resep diperoleh potensi obat-obat yang berinteraksi pada pasien gagal ginjal adalah $508(93,7 \%)$ resep, dengan 486 $(85,7 \%)$ resep memiliki tingkat keparahan signifikan. Berdasarkan penelitian Diaz et al (2020), dari 957 resep pada 112 pasien gagal ginjal kronik diperoleh potensi obat-obat yang berinteraksi adalah 928 (91\%) resep, dengan $717(77,3 \%)$ resep memiliki tingkat keparahan moderate.

Penelitian ini bertujuan untuk mengetahui karakteristik pasien, gambaran jumlah kejadian potensi interaksi obat, gambaran jenis dan jumlah obat lain yang berinteraksi, dan tingkat keparahan interaksi obat pada pasien gagal ginjal di Rawat Jalan RS “X” Kota Cirebon.

\section{METODE PENELITIAN Waktu dan Tempat Penelitian}

Penelitian ini dilakukan di Rawat Jalan RS "X" Kota Cirebon dan waktu penelitian pada bulan Januari sampai Juli tahun 2020 dengan menggunakan resep bulan Februari tahun 2020.

\section{Jenis Penelitian}

Jenis penelitian ini merupakan penelitian non eksperimental dengan metode analisis deskriptif, dan menggunakan metode pengambilan data dengan teknik random sampling secara prospektif di Rawat Jalan RS "X" Kota Cirebon.

\section{Alat}

Alat tulis, lembar pengumpulan data, dan literatur terkait.

\section{Bahan}

Bahan penelitian yang digunakan yaitu resep pasien yang didiagnosa pasien gagal ginjal di Rawat Jalan RS "X” Kota Cirebon

\section{Populasi}

Populasi dalam penelitian ini adalah resep pasien yang didiagnosa pasien gagal ginjal di Rawat Jalan RS "X"Kota Cirebon.

\section{Sampel Penelitian}

Sampel dalam penelitian ini adalah resep pasien yang didiagnosa pasien gagal ginjal di Rawat Jalan RS "X" Kota Cirebon yang memenuhi kriteria inklusi dan eksklusi sebanyak 126 resep. Kriteria inklusi: Resep pasien gagal ginjal, yang berusia 20-80 tahun, yang mengandung $\geq 2$ macam obat. Kriteria eksklusi: Resep yang tidak lengkap atau rusak.

\section{Analisa Data}

Analisis data pada penelitian ini menggunakan analisis deskriptif untuk melihat karakteristik pasien (usia dan jenis kelamin), jumlah kejadian potensi interaksi obat, tingkat keparahan interaksi obat, dan gambaran jenis dan jumlah obat yang berinteraksi pada pasien gagal ginjal kemudian dihitung persentasenya untuk setiap kategori. Data disajikan dalam Tabel 
Tabel 1. Data Karakteristik Pasien Gagal Ginjal di RS " $X$ " Kota Cirebon

\begin{tabular}{cccc}
\hline & Variabel Kelompok & Jumlah Pasien & Persentase (\%) \\
\hline \multirow{2}{*}{ Jenis } & Laki-laki & 64 & $50,79 \%$ \\
Kelamin & Perempuan & 62 & $49,21 \%$ \\
\cline { 2 - 4 } & Total & $\mathbf{1 2 6}$ & $\mathbf{1 0 0 \%}$ \\
\hline \multirow{4}{*}{ Usia } & $21-30$ & 4 & $3,17 \%$ \\
(tahun) & $31-40$ & 5 & $3,97 \%$ \\
& $41-50$ & 16 & $12,7 \%$ \\
& $51-60$ & 35 & $27,78 \%$ \\
& $61-70$ & 38 & $30,16 \%$ \\
& $71-80$ & 28 & $22,22 \%$ \\
\hline
\end{tabular}

atau gambar. Penentuan jenis interaksi/tingkat keparahan interaksi obat menggunakan aplikasi Medscape.

\section{HASIL DAN PEMBAHASAN}

Berdasarkan Tabel 1 dari 126 pasien gagal ginjal yang diberikan pengobatan, 64 pasien $(57,79 \%)$ merupakan pasien berjenis kelamin laki-laki, sedangkan pasien perempuan sebanyak 62 pasien $(49,21 \%)$. Pasien gagal ginjal yang berjenis kelamin laki-laki lebih banyak dibandingkan dengan perempuan. Hal ini sesuai dengan penelitian Pasangka dkk. (2017) yang menyatakan pasien gagal ginjal terbanyak adalah laki-laki $(55,56 \%)$, sedangkan berjenis kelamin perempuan lebih sedikit $(44,44 \%)$. Berdasarkan penelitian Maifitrianti (2016), hasil karakteristik pasien terbanyak adalah laki-laki $63,50 \%$, dan sebanyak 45 pasien $(71,42 \%)$ berusia $\geq 45$ tahun.

Berdasarkan penelitian The Third National Health and Nutrition Examination Survey (NHANES III) diperoleh hasil prevalensi gagal ginjal kronik lebih tinggi pada pasien laki laki, usia lanjut, kulit hitam dan mempunyai riwayat diagnosis dengan hipertensi (Norton et al., 2016). Hal ini menunjukkan bahwa semakin bertambah usia, semakin berkurang fungsi ginjal karena disebabkan terjadinya penurunan kecepatan ekskresi glomerulus dan penurunan fungsi tubulus pada ginjal.

Karakterisktik berdasarkan umur dari 126 pasien diketahui lebih dari $80 \%$ pasien berumur di atas 50 tahun (Tabel 1). Berdasarkan data yang diperoleh selama penelitian, semua pasien gagal ginjal merupakan pasien dengan usia dewasa, hal ini dikarenakan kecepatan filtrasi glomerular menurun sekitar $1 \%$ per tahun yang dimulai pada usia 40 tahun (Aslam et al., 2003). Berdasarkan US Renal Data System tahun 2006 resiko ESRD (End-Stage Renal Disease) di Amerika Serikat meningkat pada pria dan usia di atas 65 tahun. Tahun 2004 lebih dari $49 \%$ pasien berusia di atas 65 tahun menjalani hemodialisis (Supadmi, 2017).

Berdasarkan Tabel 2, dari 126 resep kejadian interaksi obat yang terjadi adalah sebanyak 78 lembar resep (61,9\%), sedangkan yang tidak terjadi interaksi obat sebanyak 48 lembar resep $(38,1 \%)$. Menurut penelitian Pasangka dkk. (2017), berdasarkan analisis lembar resep sebanyak 447 lembar resep diketahui potensi interaksi obat yang terjadi sebanyak 292 lembar resep $(65,32 \%)$, sedangkan yang tidak terjadi 155 lembar resep $(34,76 \%)$. Lebih lanjut pada penelitian Diaz et a.l (2020), dari 957 resep pada 112 pasien gagal ginjal kronik diperoleh potensi obat-obat yang berinteraksi adalah 928 (91\%) resep. 
Tabel 2. Jumlah Kejadian Potensi Interaksi Obat Pada Pasien Gagal Ginjal di RS "X” Kota Cirebon

\begin{tabular}{ccc}
\hline Kriteria & $\begin{array}{c}\text { Jumlah } \\
\text { Lembar } \\
\text { Resep }\end{array}$ & Persentase \\
\hline Ada Interaksi Obat & 78 & $61,9 \%$ \\
Tidak Ada Interaksi Obat obat & 48 & $38,1 \%$ \\
Total & 126 & $100 \%$ \\
\hline
\end{tabular}

Tabel 3. Tingkat Keparahan Kejadian Interaksi Obat pada Resep Pasien Gagal Ginjal di RS "X" Kota Cirebon

\begin{tabular}{ccc}
\hline Kriteria & Jumlah Kejadian Interaksi & Persentase \\
\hline Serius & 3 & $1,51 \%$ \\
Monitor & 128 & $64,65 \%$ \\
Minor & 67 & $33,84 \%$ \\
\hline Jumlah & $\mathbf{1 9 8}$ & $\mathbf{1 0 0 \%}$ \\
\hline
\end{tabular}

Tabel 4. Kejadian Interaksi Obat Tiap Lembar Resep pada Pasien Gagal Ginjal di RS “X” Kota Cirebon

\begin{tabular}{ll}
\hline Kriteria & Jumlah Kejadian \\
\hline $\begin{array}{l}\text { Jumlah kejadian interaksi obat } \\
\begin{array}{l}\text { Jumlah lembar resep yang terdapat kejadian interaksi } \\
\text { obat }\end{array}\end{array}$ & 78 \\
\hline Rerata & $\mathbf{2 , 5 3 \approx 3}$ \\
\hline
\end{tabular}

Pada Tabel 3 diketahui kejadian interaksi obat berdasarkan tingkat keparahan serius sebanyak 3 kejadian (1,51\%), tingkat keparahan monitor ketat sebanyak 128 kejadian $(64,65 \%)$, dan tingkat keparahan minor sebanyak 67 kejadian $(33,84 \%)$.

Dengan demikian jumlah tingkat keparahan kejadian interaksi obat terbanyak adalah monitor ketat, disusul dengan tingkat keparahan minor, dan serius. Kategori monitor ketat artinya pemberian kombinasi obat yang memberikan efek yang signifikan secara klinis.

Hasil tersebut sejalan dengan penelitian Pasangka dkk. (2017) yang menyebutkan hasil interaksi monitor ketat adalah sebanyak 206 kejadian $(70,54 \%)$, minor 64 kejadian $(21,91 \%)$ dan serius sebanyak 22 kejadian (7,54\%). Berdasarkan penelitian Kono (2019) diperoleh hasil interaksi obat potensial ditemukan pada $85,7 \%$ sampel dengan tingkat keparahan minor sebesar 26\%, sedang/moderate sebesar $68 \%$, dan mayor sebesar 5\%. Lebih lanjut menurut hasil penelitian Maifitrianti (2016) sebanyak 334 kasus $(75,39 \%)$ merupakan interaksi obat dengan tingkat keparahan moderat. Sedangkan hasil penelitian Adibe et al. (2017) diperoleh hasil dari 169 pasien diperoleh 749 kejadian interaksi obat, dengan 525 kejadian $(70,09 \%)$ tingkat keparahan signifikan.

Pada Tabel 4 dari total jumlah resep 126 lembar yang terdapat interaksi obat sebanyak 78 lembar resep dan jumlah kejadian interaksi obat terdapat 198 kejadian interaksi, dari data tersebut memiliki rata-rata kejadian interaksi obat dalam lembar resep sejumlah 3 kejadian interaksi. Berdasarkan penelitian Rama et al (2012) dari 205 resep pasien penyakit ginjal kronis diperoleh 474 kejadian interaksi obat, dengan 19,62\% memiliki tingkat keparahan mayor.

Berdasarkan Tabel 5 dari 78 kejadian interaksi obat yang terjadi pada pasien gagal ginjal, diketahui jenis dan jumlah obat yang berinteraksi terbanyak adalah furosemid + 
Tabel 5. Jenis Dan Jumlah Obat Yang Berinteraksi Pada Pasien Gagal Ginjal di RS "X" Kota Cirebon Berdasarkan Jumlah Kejadian Interaksi Obat

\begin{tabular}{|c|c|c|c|c|}
\hline No & Nama Obat & $\begin{array}{l}\text { Tingkat } \\
\text { Keparahan }\end{array}$ & $\begin{array}{l}\text { Jumlah } \\
\text { Interaksi Obat }\end{array}$ & $\begin{array}{l}\text { Persentase } \\
(\%)\end{array}$ \\
\hline 1 & Acarbose + Insulin Aspart & Monitor & 4 & $5,13 \%$ \\
\hline 2 & Acarbose + Insulin Detemir & Monitor & 2 & $2,56 \%$ \\
\hline 3 & Amlodipine + Metformin & Monitor & 3 & $3,85 \%$ \\
\hline 4 & Amlodipine + Simvastatin & Serius & 3 & $3,85 \%$ \\
\hline 5 & Aspirin + Folic Acid & Minor & 1 & $1,28 \%$ \\
\hline 6 & Aspirin + Furosemid & Monitor & 1 & $1,28 \%$ \\
\hline 7 & Bisoprolol + Amlodipine & Monitor & 10 & $12,82 \%$ \\
\hline 8 & Bisoprolol + Furosemid & Monitor & 2 & $2,56 \%$ \\
\hline 9 & Bisoprolol + Ibuprofen & Monitor & 1 & $1,28 \%$ \\
\hline 10 & Bisoprolol + Telmisartan & Monitor & 2 & $2,56 \%$ \\
\hline 11 & Calcium Carbonat + Allopurinol & Monitor & 2 & $2,56 \%$ \\
\hline 12 & Calcium Carbonat + Amlodipine & Monitor & 8 & $10,26 \%$ \\
\hline 13 & Calcium Carbonat + Bisoprolol & Monitor & 3 & $3,85 \%$ \\
\hline 14 & Candesartan + Aspirin & Monitor & 1 & $1,28 \%$ \\
\hline 15 & Candesartan + Bisoprolol & Monitor & 4 & $5,13 \%$ \\
\hline 16 & Candesartan + Furosemid & Monitor & 21 & $26,92 \%$ \\
\hline 17 & Candesartan + Hydrochlortiazide & Monitor & 2 & $2,56 \%$ \\
\hline 18 & Candesartan + Ibuprofen & Monitor & 5 & $6,41 \%$ \\
\hline 19 & Candesartan + Insulin Aspart & Monitor & 4 & $5,13 \%$ \\
\hline 20 & Candesartan + Insulin Detemir & Monitor & 1 & $1,28 \%$ \\
\hline 21 & Candesartan + Meloxicam & Monitor & 5 & $6,41 \%$ \\
\hline 22 & Candesartan + Pottasium Chloride & Monitor & 1 & $1,28 \%$ \\
\hline 23 & Candesartan + Spironolactone & Monitor & 1 & $1,28 \%$ \\
\hline 24 & Carbamazepine + Folic Acid & Minor & 1 & $1,28 \%$ \\
\hline 25 & Furosemid + Calcium Carbonate & Minor & 9 & $11,54 \%$ \\
\hline 26 & Furosemid + Folic Acid & Minor & 32 & $41,02 \%$ \\
\hline 27 & Furosemid + Thiamine & Minor & 3 & $3,85 \%$ \\
\hline 28 & Gabapentin + Cyanocobalamin & Minor & 1 & $1,28 \%$ \\
\hline 29 & Hydrochlortiazide + Acarbose & Minor & 2 & $2,56 \%$ \\
\hline 30 & Hydrochlortiazide + Folic Acid & Minor & 1 & $1,28 \%$ \\
\hline 31 & $\begin{array}{l}\text { Hydrochlortiazide }+ \text { Insulin } \\
\text { Aspart }\end{array}$ & Minor & 2 & $2,56 \%$ \\
\hline 32 & Ibuprofen + Carbamazepine & Monitor & 1 & $1,28 \%$ \\
\hline 33 & Ibuprofen + Furosemid & Monitor & 1 & $1,28 \%$ \\
\hline 34 & Ketorolac + Furosemid & Monitor & 1 & $1,28 \%$ \\
\hline 35 & Ketorolac + Propanolol & Monitor & 1 & $1,28 \%$ \\
\hline 36 & Ketorolac + Vitamin K & Monitor & 1 & $1,28 \%$ \\
\hline 37 & Lansoprazole + Cyanocobalamin & Minor & 1 & $1,28 \%$ \\
\hline 38 & Meloxicam + Bisoprolol & Monitor & 2 & $2,56 \%$ \\
\hline
\end{tabular}


Tabel 5. Jenis Dan Jumlah Obat Yang Berinteraksi Pada Pasien Gagal Ginjal di RS “X” Kota Cirebon Berdasarkan Jumlah Kejadian Interaksi Obat (Lanjutan)

\begin{tabular}{|c|c|c|c|c|}
\hline No & Nama Obat & $\begin{array}{l}\text { Tingkat } \\
\text { Keparahan }\end{array}$ & $\begin{array}{l}\text { Jumlah } \\
\text { Interaksi Obat }\end{array}$ & $\begin{array}{l}\text { Persentase } \\
(\%)\end{array}$ \\
\hline 39 & Meloxicam + Furosemid & Monitor & 1 & $1,28 \%$ \\
\hline 40 & Metformin + Folic Acid & Minor & 5 & $6,41 \%$ \\
\hline 41 & Omeprazole + Alprazolam & Minor & 2 & $2,56 \%$ \\
\hline 42 & Pottasium Chloride + Acarbose & Minor & 1 & $1,28 \%$ \\
\hline 43 & $\begin{array}{l}\text { Pottasium Chloride + } \\
\text { Hydrochlortiazide }\end{array}$ & Monitor & 1 & $1,28 \%$ \\
\hline 44 & $\begin{array}{l}\text { Pottasium Chloride + Insuline } \\
\text { Aspart }\end{array}$ & Minor & 1 & $1,28 \%$ \\
\hline 45 & Propanolol + Furosemid & Monitor & 1 & $1,28 \%$ \\
\hline 46 & Propanolol + Spironolactone & Monitor & 1 & $1,28 \%$ \\
\hline 47 & Sodium Bicarbonat + Allopurinol & Monitor & 14 & $17,95 \%$ \\
\hline 48 & Sodium Bicarbonat + Aspirin & Minor & 1 & $1,28 \%$ \\
\hline 49 & Sodium Bicarbonat + Bisoprolol & Monitor & 12 & $15,38 \%$ \\
\hline 50 & Sodium Bicarbonat + Ferrous & Monitor & 1 & $1,28 \%$ \\
\hline 51 & Sodium Bicarbonat + Gabapentin & Monitor & 3 & $3,85 \%$ \\
\hline 52 & Spironolactone + Furosemid & Monitor & 2 & $2,56 \%$ \\
\hline 53 & Spironolactone + Ketorolac & Monitor & 1 & $1,28 \%$ \\
\hline 54 & Sucralfate + Furosemid & Monitor & 1 & $1,28 \%$ \\
\hline 55 & Sucralfate + Lansoprazole & Minor & 4 & $5,13 \%$ \\
\hline \multicolumn{3}{|c|}{ Total } & 198 & $100 \%$ \\
\hline
\end{tabular}

interaksi $(41,02 \%)$, candesartan + furosemid 21 potensi kejadian interaksi $(26,92 \%)$, Sodium Bicarbonat + Allopurinol 14 potensi kejadian interaksi $(17,95 \%)$. Sebagian pasien memiliki diagnosa gagal ginjal dan memiliki penyakit penyerta seperti hipertensi, diabetes mellitus, udem paru-paru dan asidosis metabolik.

Berdasarkan penelitian Fatimah (2019) diperoleh hasil potensi interaksi obat paling banyak ditemukan adalah pasangan furosemid dan ranitidin dengan efek peningkatan kadar AUC furosemid.

Potensi interaksi obat dengan tingkat keparahan serius adalah simvastatin dan amlodipine dengan mekanisme interaksi farmakokinetik yang dapat berpotensi menyebabkan efek rhabdomyolysis yang artinya suatu sindrom atau kumpulan gejala yang disebabkan oleh kerusakan dan kematian jaringan otot rangka. Amlodipine
Potensi interaksi obat yang banyak terjadi yaitu furosemid dan asam folat sebanyak 32 potensi kejadian interaksi $(41,02 \%)$. Kejadian tersebut termasuk dalam tingkat keparahan minor, mekanisme yang terjadi furosemid menurunkan kadar asam folat dengan meningkatkan pembersihan ginjal (Medscape.com, 2019).

dapat meningkatkan konsentrasi plasma dari simvastatin dan berpotensi menginduksi terjadinya miopati. Mekanisme terjadinya yaitu melalui usus dan hati dengan enzim CYP450 3A4. Oleh karena itu pemberian dosis simvastatin tidak lebih dari $20 \mathrm{mg} / \mathrm{hari}$ bila akan digunakan bersama amlodipine (Drugs.com, 2016).

\section{KESIMPULAN}

Pasien gagal ginjal terbanyak adalah lakilaki sebanyak 64 orang $(50,79 \%)$, usia paling banyak pada rentang umur 61-70 tahun 
sebanyak 38 orang $(30,16 \%)$. Terdapat interaksi obat pada 78 lembar resep $(61,9 \%)$, dengan tingkat keparahan interaksi obat paling banyak adalah monitor ketat/ signifikan sebanyak 128 kejadian (64,65\%). Rerata kejadian interaksi obat per lembar resep sebanyak 3 kejadian interaksi. Jenis dan jumlah obat yang paling banyak berinteraksi adalah obat furosemide+folic acid sebanyak 32 potensi kejadian interaksi (41,02\%).

\section{Daftar Pustaka}

Adibe, M.O., Ewelum, P.C., Amorha, K.C., 2017. Evaluation of drug-drug interactions among patients with chronic kidney disease in a South-Eastern Nigeria tertiary hospital: a retrospective study. The Pan African Medical Journal, 28: 199.

Aslam, M., Tan, C.K., Prayitno, A., 2003. Farmasi klinis: menuju pengobatan rasional dan penghargaan pilihan pasien. Jakarta: PT. Elex Media Komputindo. Hal. 18-19, 137-141.

Bailie, G.R. Johnson, C.A., Mason, N.A., Peter, W.L.St., 2004. Medfacts pocket guide of drug interaction. Second Edition. Bone Care International, Nephrology Pharmacy Associated, Inc : Middleton

Busari, A. A., Oreagba, I. A., Oshikoya, K.A. Kayode, M. O., Olayemi, S. O., 2019. High risk of drug-drug interactions among hospitalized patients with kidney diseases at a nigerian teaching hospital: A Call for action. Nigerian Medical Journal, Nov-Dec; 60(6): 317-25.

Bushra R., Nousheen A., Arshad Y. K.. 2011. Food-drug interactions. Oman Medical Journal.

Cahyaningsih, D., Niken., 2011. Hemodialisis (cuci darah), Yogyakarta: Mitra Cendikia.

Dalimunthe, A., 2009. Interaksi obat pada anti mikroba, Departemen Farmakologi, Fakultas Farmasi, Universitas Sumatra Utara, Medan.

Diaz, G. S., Pico, A.M.P., Santisteban, M.A.S., Bernalt, V.G., Mayordomo, R., Dorado, P., 2020. Prevalence of potential drug-drug interaction risk among chronic kidney disease patients in a spanish hospital. Pharmaceutics. 2020 Aug; 12(8): 713.

Drugs.com, (2016). Drug interaction checker. https://www.drugs.com/drug_interactions.html

Fatimah, S., 2019, Studi potensi interaksi obat pada terapi pasien penyakit ginjal kronis (PGK) di instalasi rawat inap RSUD Jombang tahun 2016. Tesis. UIN Malang.

Gitawati, R., 2008. Interaksi obat dan beberapa implikasinya. Media Litbang Kesehatan, $\begin{array}{lllll}\text { Volume } & \text { XVIII } & \text { Nomor } & 4 . & \text { P: }\end{array}$ http://ejournal.litbang.kemkes.go.id/index.php/MPK/article/view/1086

Indonesian Renal Registry (IRR), 2013. Report of Indonesia Renal Registry (2012). Perhimpunan Nefrologi Indonesia (PERNEFRI) 5th Edition.

Kementerian Kesehatan RI, 2013. Riset Kesehatan Dasar (RISKESDAS) 2013, Jakarta.

Kenward, R., dan Tan, C.K, 2003. Penggunaan obat pada gangguan ginjal, dalam Aslam Farmasi Klinis: Menuju Pengobatan Rasional dan Penghargaan Pilihan Pasien 2003, 140153, PT. Elex Media Komputindo Gramedia, Jakarta.

Kono, B.R., 2019. Analisis drp interaksi obat pasien penyakit ginjal kronik di instalasi rawat inap RSUD Profesor Dr. W.Z. Johannes Kupang. Tesis. Universitas Citra Bangsa. 
Maifitrianti, 2016. Identifikasi interaksi obat-obat potensial pada pasien gagal ginjal kronik RSPAD Gatot Soebroto. Farmasains, Vol. 3, No.2: 59-63.

Mariam, S. 2016. Evaluasi kejadian interaksi obat pada pasien rawat inap geriatri penderita gagal jantung. Skripsi. Sekolah Tinggi Ilmu Farmasi dan Industri, Bogor.

Medscape, 2019. Medscape Reference, Aplikasi Medscape. [Akses 2020]

National Kidney Foundation, 2016. About Chronic Kidney Disease; 2016 [dikutip 29 Jan 2017] : https://www.kidney.org/kidneydisease/aboutckd

Norton, J.M., Moxey-Mims, M.M., Eggers, P.W., Narva, A.S., Star, R.A., Kimmel, P.L., and Rodgers, G.P., 2016. Social determinants of racial disparities in CKD. JASN, September 2016, 27 (9) 2576-95, DOI: https://doi.org/10.1681/ASN.2016010027

Pasangka, I.T., Tjitrosantoso, H., Lolo, W.A., 2017. Identifikasi potensi interaksi obat pada pasien gagal ginjal, Jurnal Ilmiah Farmasi, Vol. 6 No. 4. https://ejournal.unsrat.ac.id/index.php/pharmacon/article/view/17727/17252.

Prasetya, A.A.N.P.R., Karsana, A.A.R., dan Swastini., D.A., 2012. Kajian interaksi obat pada pengobatan pasien gagal ginjal kronis hipertensi, Jurnal Farmasi Udayana, Desember 2012: p9-15.

Rahardjo, P., 2006. Hemodialisis dalam ilmu penyakit dalam. Jakarta: Penerbit FKUI: Jilid 1, hal 579.

Rama, M., Viswanathan, G., Acharya,D., Attur, PR., Reddy, N P., Raghavan,VS., 2012. Assessment of drug-drug interaction among renal failure patients of nephrology ward in a South Indian tertiary care hospital. Indian journal of pharmaceutical Sciences. 74(1): 63-68

Stamatakis, M.K., 2008. Acute renal failure. In M. A. C. Burns., Wells, B. G., Schwinghammer, T. L., Malone, P.M., Kolesar, J.M. \&amp; J. T. Dipiro., eds. Pharmacotherapy Principles and Practice. New York: The McGraw-Hill Companies, p. 361-370.

Supadmi, W., Jumiati, 2017. Interaksi obat pada pasien gagal ginjal kronik di bangsal hemodialisis Rumah Sakit Happyland Yogyakarta. Akfarindo, Vol. 2 No. 2 2017: 24-31.

Wilson, L. M. 2005. Gagal Ginjal Kronik. Dalam: Wilson, L.M., Price, S.A., Penyunting. Patofisiologi: konsep klinis proses-proses penyakit edisi ke-6. Jakarta: ECG, hal. 912-47. 